\title{
Cryptococcosis, A Risk for Immunocompromised and Immunocompetent Individuals
}

\author{
Maurimélia Mesquita da Costa ${ }^{1,2}$, Francisco Martins Teixeira ${ }^{1}$, Taysa Ribeiro Schalcher ${ }^{1}$, \\ Mioni Thielli Figueiredo Magalhães de Brito ${ }^{1}$, Erika Silva Valério ${ }^{1}$ and Marta Chagas Monteiro*,1,2 \\ ${ }^{1}$ Faculty of Pharmacy, Program in Pharmaceutical Science, Federal University of Pará (UFPA), Pará, Brazil \\ ${ }^{2}$ Evandro Chagas Institute, Bacteriology and Mycology Section, Mycology Laboratory, Belém, Pará, Brazil. Program in \\ Biology of Infectious and Parasitic Agents, Institute of Biological Sciences Federal University of Pará (UFPA), Pará, \\ Brazil
}

\begin{abstract}
The genus Cryptococcus includes at least 37 different species, of which, two are important human pathogens: Cryptococcus neoformans and Cryptococcus gattii. These fungi are opportunistic pathogens and etiologic agents of cryptococcosis disease in humans and animals. A variety of virulence factors interfere with the establishment of cryptococcal infection is usually acquired via inhalation of environmental basidiospores or desiccated yeasts. Cryptococcosis has gained medical importance over the last decade due to the AIDS pandemic, and become an emerging pathogen of immunocompetent individuals, especially in children. This disease in humans may involve every tissue, including cutaneous and pulmonary sites, but the most serious manifestation is central nervous system involvement with meningoencephalitis. In this review, we briefly described the taxonomy, the fungus biology, epidemiology and clinical manifestations of cryptococcosis in immunocompetent and immunocompromised individuals.
\end{abstract}

Keywords: Cryptococcus neoformans, Cryptococcus gattii, cryptococcosis, immunocompetent individuals, immunocompromised individuals.

\section{INTRODUCTION}

Cryptococcosis is caused by the basidiomycetous yeasts Cryptococcus neoformans and Cryptococcus gattii [1], which have a predilection for the pulmonary and central nervous systems $[2,3]$. This considerable impact on human health can be attributed to the number of virulence factors found in C. gattii and C. neoformans which share structural and physiological characteristics that allow them to invade and survive in host tissues [3]. The major virulence factors associated with Cryptococcus are the ability to grow at $37^{\circ} \mathrm{C}$ [4], the production of the pigment melanin [5-7] and the formation of a polysaccharide capsule [8]. The number of infections caused by Cryptococcus has advanced considerably around the world in recent years. This perception comes from the rapidly increasing number of hospitalized patients due to complications caused by infections attributed to this type of microorganism $[9,10]$. $C$. neoformans varieties are opportunistic pathogens, which mainly cause meningoencephalitis predominantly in immunocompromised individuals [11]. C. gattii has a more aggressive behavior and causes infections more frequently in immunocompetent humans and animals $[12,13]$. In recent years, several excellent recent reviews for further information about other aspects of cryptococcal virulence,

*Address correspondence to this author at the Departamento de Farmácia, Universidade Federal do Pará - UFPA, Belém, PA, Brazil;

Tel: +55 91 3201-7202; Fax: +55 91 3201-7201;

E-mail: martachagas2@yahoo.com.br sexual development and signaling, and immune response have been published. In this review, we briefly describe the taxonomy, the fungus biology, epidemiology and clinical manifestations of cryptococcosis in immunocompetent and immunocompromised individuals. We performed a comprehensive review of original research and reports regarding the cases of cryptococcosis in the world, covering publications up to 2013 using the databases PubMed, MEDLINE, Google Scholar and SciELO.

\section{TAXONOMY}

The genus Cryptococcus is classified in the order Tremellales, class Tremellomycetes, phylum Basidiomycota and the kingdom Fungi. It includes at least 37 different species, of which, two are important human pathogens: Cryptococcus neoformans and Cryptococcus gattii [1]. They are characterized as basidiomycetous encapsulated budding yeasts commonly involved in the etiology of infection affecting the pulmonary and central nervous systems $[2,14]$. Typically, C. neoformans has been associated with severe cases of meningitis in immunocompromised patients, while $C$. gattii has been shown to be an important cause of infections in immunocompetent individuals [11, 15]. $C$. neoformans and $C$. gattii have now been divided into separate species, although most clinical laboratories will not routinely identify Cryptococcus to the species level [16].

C. neoformans was originally named Saccharomyces neoformans by Sanfelice in 1894 after the microorganism was isolated from peach juice [17]. Since then, several studies showed that the yeast was related to different 
infections, which led to the creation of a different species names; however, this was later proven to be the same microorganism. In 1901, Vuillemin proposed a new genus, named Cryptococcus, to include these yeasts, based on the differences found in morphological aspects when compared to Saccharomyces sp. [18]. The teleomorph [sexual state] of C. neoformans was identified in 1975 by Kwon-Chung and described as Filobasidiella neoformans as a result of the mating of two strains of serotype D [19]. Currently, there are three recognized varieties of $C$. neoformans: $C$. neoformans var. grubii [serotype A], C. neoformans var. neoformans [serotype D] and hybrid serotype AD [20].

The matings between two other compatible strains [serotypes B and C] produced a different teleomorph named Filobasidiella bacillispora [21]. Several studies [12,22-25] then revealed the huge diversity not only in this teleomorph, but also in its anamorph, which was named Cryptococcus bacillispora, considering the differences found in aspects such as physiology, biochemistry, epidemiology, ecology and genetics [25]. Later, C. bacillispora was suggested as a variety of $C$. neoformans named $C$. neoformans var. gattii [26], which in 2002, was finally proposed to be the species Cryptococcus gattii [16].

Recently, molecular studies using different methods, such as PCR fingerprinting, Amplified Fragment Length Polymorphisms [AFLP] analysis, Restriction Fragment Length Polymorphism [RFLP] and Multilocus Sequence Typing [MLST], have shown that $C$. neoformans and $C$. gattii can also be grouped in at least eight cryptic species defined as molecular types, therefore characterizing intraspecies and inter-species genetic diversity [27]. Thus, although other subgroups exist, the main genotypes recognized so far are: $C$. neoformans var. grubii, serotype A, molecular types VNI=AFLP1 and VNII=AFLP1A; the hybrid serotype AD corresponds to VNIII=AFLP3; and $C$. neoformans var. neoformans, serotype $\mathrm{D}$, which consists of VNIV=AFLP2.In both serotypes B or C of $C$. gattii, the molecular types established are VGI=AFLP4, VGII=AFLP6, VGIII=AFLP5, and VGIV=AFLP7 [28]. The pathogenic implications of these molecular types will require more studies, since the epidemiological distribution is not completely known. However, it has recently been shown that the genotype VGIIa presents higher virulence than VGIIb isolates of C. gattii [29].

\section{BIOLOGICAL CHARACTERISTICS AND VIRULENCE FACTORS}

Cryptococcosis is a systemic mycosis that occurs in humans caused by either $C$. neoformans or $C$. gattii species, which has a predilection for the central nervous system and is generally believed to be acquired through the inhalation of airborne fungal propagules [30,31]. However, there are some intrinsic characteristics of each species that influence their epidemiology and ecological niche, as well as the clinical course of the disease. Typically, $C$. neoformans varieties cause disease predominantly in immunocompromised individuals [11]. $C$. neoformans var. grubii is distributed worldwide and is considered the main cause of cryptococcosis in HIV-infected patients, while $C$. neoformans var. neoformans is more prevalent in South America and Europe [32,33]. Bird droppings (mainly pigeons) and soil contaminated with avian fecal material are the main sources of transmission of $C$. neoformans $[31,32,34]$, but this fungus was also isolated from decaying wood contained in hollow parts of living trees [35,36].

C. gattii has a more aggressive behavior and causes infections more frequently in immunocompetent humans and animals [12,13,31,37-39]. C. gattii infections are reported to be more resistant to antifungal chemotherapy and, thus, require more aggressive and prolonged treatment $[12,13,37,40]$. C. gattii was initially thought to be found only in tropical subtropical climates [13,16,31,40,41]; however, after the ongoing outbreak occurred in Vancouver Island in British Columbia, Canada it was determined that this species is also present in temperate climates $[42,43]$. In this regards, C. gattii has been found to be endemic in many regions such as Australia and New Zealand, Papua New Guinea, South and Southeast Asia (Cambodia, Malaysia, Thailand, Vietnam, People's Republic of China, Taiwan, Singapore, Nepal, and the Indian subcontinent), parts of Latin America (Argentina, Brazil, Colombia, Uruguay, Paraguay, Peru, and Venezuela), southern California, Mexico, Hawaii, Central and South Africa, and certain parts of Europe (Austria, Germany, France, Italy, Greece, and Spain) [40].

C. gattii was believed to be restricted to the tropics and subtropical regions associated with species of Eucalyptus trees. The distribution of $C$. gattii has been associated with Eucalyptus trees from Australia that are exported throughout the world $[31,40,41,44]$. However, recent studies have also documented the dispersal of $C$. gattii through other trees, bird excreta, soil and human interactions with the environment [14,45-47]. Moreover, C. gattii serotypes frequently cause disease in healthy individuals and also show the ability to infect many kinds of animal, including wild felines, dogs, cats and birds, among others [48].

These fungi can cause infection in humans and animals and have been reported sporadically in wild animals, including several exotic species [30,49-53], and in domestic animals [54-57]. However, infection is most common systemic mycosis in cats [55], with the most frequently isolated causative agent in these cases being $C$. neoformans. While cats and occasionally dogs can develop skin infections due to this yeast, the aerosols formed from these injuries do not appear to be a source of infection for people via touch. On the other hand, recent studies have reported that a Cryptococcosis outbreak in a human Vancouver Island (British Columbia, Canada) was associated with the elimination of the yeast $C$. gattii in dogs and cats with asymptomatic infection or colonization of the fungus in the nose, suggesting that these pets can be possible carriers of this species to humans [57].

Although not well established yet, it is assumed that infection starts when humans inhale microscopic-size propagules of the fungi (basidiospores $<2 \mu \mathrm{m}$ in size) found in the environment. The spores seem to be more suitable for both air dispersal and survival in the soil and can be transferred to the alveoli of the lungs where they can cause pneumonia; subsequently, the microorganisms can spread to the central nervous system, causing meningoencephalitis [58]. However, it is also considered that desiccated yeasts play a role in transmission because of their small size $(\sim 3 \mu \mathrm{m}$ compared with 4-10 $\mu \mathrm{m}$ for actively growing yeast cells) despite their fragility. For C. neoformans, the main source of 
infectious propagules is pigeon guano, although the species can also be isolated from other avian guano, soil and decaying wood $[35,44,59]$. On the other hand, C. gattii has been mostly isolated from several species of trees in many countries, such as Eucalyptus camaldulensis and Eucalyptus blakelyi in Australia [60], Moquilea tomentosa [pottery tree] and Cassia grandis [pink shower tree] in Brazil [35,47] and Terminalia catappa [almond tree] in Colombia [61].

This considerable impact on human health can be attributed to the number of virulence factors found in $C$. gattii and $C$. neoformans which share structural and physiological characteristics that allow them to invade and survive in host tissues [3]. Moreover, differences in the presentation of infections caused by $C$. gattii and $C$. neoformans may be due, in part, to a deficiency in proteinase production by the former, which may limit the ability of $C$. gattii to disseminate locally and into circulation. $C$. gattii produces circumscribed lesions (cryptocococcomas) more often than C. neoformans [62].

Cryptococcus is an encapsulated fungal organism and the cryptococcal capsule is one of the most important virulence factors to dissemination and survival of this microorganism inside immunocompetent and immunocompromized host tissue, according to studies that demonstrated a loss of virulence in acapsular strains or strains with defective capsule production [63, 64]. The capsule works like a physical barrier made of polysaccharides rich in mannan residues with important properties [8].

Fig. (1) shows the principal virulence factor of these species is the presence of a polysaccharide capsule which is basically composed of glucuronoxylomannan (GXM) with smaller proportions of galactoxylomannan (GalXM) and mannoprotein [65]. GXM and GalXM have weak antigenic functions and hide cellular components which could be recognized, like pattern molecular associated to pathogens (PAMPs) by the receptors of innate immunity, including Toll-like receptors, and can induce danger signals to the host immune response $[3,66,68]$. The capsule plays a major role in the immune response of the host by interference with phagocytosis and the recruitment of inflammatory cells (macrophages, DCs and neutrophils), decreasing antibody production in response to infection and activation of complement via the classical pathway, as well as suppressing the delayed-type hypersensitivity response [3,8,66-68].

Other virulence factors are the presence of melanin, which is shown to contribute to nervous system tropism [69] and protect against oxygen and nitrogen free radicals $[6,70]$; the growth at physiological temperature $\left(37^{\circ} \mathrm{C}\right)$, which contributes to survival and persistence in the host $[4,70]$; and the production of extracellular enzymes such as laccases, which are the enzymes responsible for melanin biosynthesis in the cell wall and, together with urease, induce the macrophages to produce IL-10 and TGF- $\beta$ [5-7,70,71]. Phospholipase B is involved in cell wall integrity and fungal invasion and dissemination in the host lung tissue. The Th2 polarization observed in cryptococcosis could be explained by phospholipase participation that induces pulmonary eosinophilia in mice infected with the wild type strain but not with the phospholipase-deleted mutant strain [72]. Urease, which catalyzes the hydrolysis of urea to ammonia and carbamate, increases the ability of $C$. neoformans to invade the central nervous system, among other roles [73]. The urease expression by virulent strains has been shown to be important in the traffic of DCs to lymph nodes in a murine model, with inadequate migration of immature DC resulting in Th2 response and pulmonary pathology in C57BL/6 mice infected with Cryptococcus [74]. Finally, pheromone production in sexual reproduction can generate hybrid organisms that are potentially more virulent $[75,76]$.

\section{EPIDEMIOLOGY OF CRYPTOCOCCOSIS}

Cryptococcosis occurrence has been considered sporadic, although of worldwide distribution. In non-HIV infected individuals, incidence rates of $0.2-0.9 \%$ have been reported in the United States, mainly in organ transplant recipients [77]. Nevertheless, the infection prevalence can reach $15 \%$ when considering patients with AIDS accessing antiretroviral therapy [78]. The percentages of disease can vary according to many factors such as clinical presentation. A study in Uganda showed that the prevalence of pulmonary cryptococcosis among HIV-infected patients hospitalized with pneumonia who underwent bronchoscopy was $11 \%$ [79]. Balkhair [80] reported that Cryptococcus meningitis accounted for $21 \%$ of the HIV patients, while Indian studies showed an incidence of cryptococcal infection (including meningitis) of $6-8 \%, 5-11 \%$ in the USA, $33 \%$ in Africa, and $28.5 \%$ in Thailand [80-82].

The prevalence ratings are also different for both species and their subgroups. In this regard, a lot of studies have reported the local distributions of cryptococcosis considering the etiological aspect in order to establish the real epidemiology of $C$. neoformans and $C$. gattii. In French Guiana, a retrospective study from 1998 to 2008 was performed on all patients with cryptococcosis who were admitted to hospitals, and showed that $C$. neoformans var. grubii was recovered with a frequency of $77.3 \%$ and was mainly isolated from patients with AIDS, whereas $C$. gattii was responsible for $22.7 \%$ of the cases and was strictly isolated from HIV-negative patients with no apparent risk factors [83]. In the Southeast and South regions of Brazil, human cryptococcosis is predominantly caused by $C$. neoformans serotype A, VNI and is associated with AIDS [84]. Conversely, British Columbia, Canada, has the largest reported population of Cryptococcus gattii-infected persons worldwide with the predominance of VGIIa strain, with a total of 218 cases reported [average annual incidence 5.8 per million persons] during the period from 1999 to 2007 [85]. Since 2005, the $C$. gattii outbreak has continued to expand throughout this temperate region, with outbreak isolates being reported in the United States involving both the VGIIa/major genotype and the novel VGIIc genotype, which are clonally derived and highly virulent in host models of infection [86]. A study realized in Brazil showed that $C$. gattii was the main causative agent of meningitis in the HIVnegative patients with high frequency of cryptococcal meningitis in children (18.6\%) suggesting that cryptococcal infection occurs early in life in this region [87]. Epidemiological studies in these regions showed that the molecular type VGII is the main agent for cryptococcal meningitis in young adults and children [87, 88].

The morbidity and mortality associated with cryptococcosis is very significant. It is estimated that $C$. 


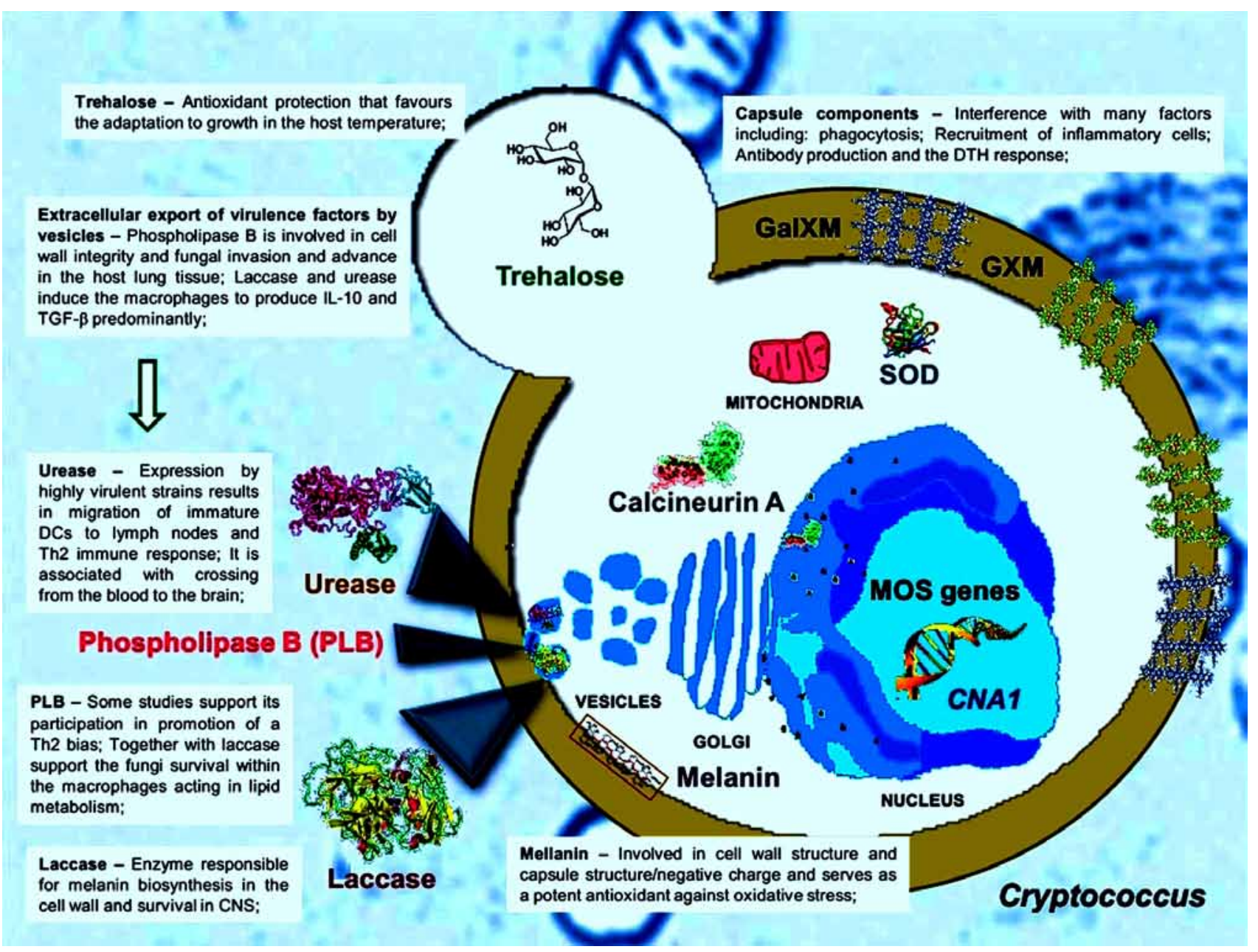

Fig. (1). Principal virulence factors of Cryptococcus species.

neoformans causes about 1 million new cases of meningoencephalitis globally per year in patients with AIDS, leading to approximately 625,000 deaths [9]; a higher prevalence is found in sub-Saharan Africa [9, 20, 89]. A study conducted in the United States of America in the period from 1997 to 2009 analyzed the incidence of cryptococcal meningitis in 18 States using the Agency for Healthcare and Research Quality (AHRQ) State Inpatient Databases (SID) datasets and identified 30,840 hospitalizations. Of those, 24,151 (79.4\%) were associated with HIV, while $6,689(21.6 \%)$ were not associated with HIV/AIDS. In-hospital mortality was found to be $12.4 \%$ for women and $10.8 \%$ for men, with a total of 3,440 deaths [90].

Factors associated with high mortality of cryptococcosis include the presence of immunodeficiency, particularly HIV1 infection. In these patients, mortality is even higher when they present low CD4+ cells counts $\left(<50\right.$ cells $\left./ \mathrm{mm}^{3}\right)[91$, 92] In this regard, an important measure to reduce mortality due to cryptococcal disease is to implement early diagnosis, which can be achieved by antigen screening in order to establish anti-fungal therapy in those patients with a positive test in areas with a high prevalence of cryptococcal disease [93].

It is worrying that, despite access to advanced medical care and the availability of HAART, the mortality rate of acute cryptococcal meningoencephalitis after 3 months of treatment is approximately $20 \%$ [94,95]. Moreover, without specific antifungal treatment for cryptococcal meningoencephalitis in some HIV-positive populations, mortality rates may reach $100 \%$ within 2 weeks after the onset of clinical symptoms and access to health care [16]. Clearly, a careful evaluation of cryptococcosis is critical to the success of curing the disease [39]. Disseminated cryptococcosis is also commonly found in patients with AIDS; studies have reported that this form of cryptococcosis was identified in $8 \%$ of cases from India [96] 8-14\% of cases from United States [97], 10\% from Mexico [98], 3-19\% from Africa [99,100], 3-4\% from Brazil [84,101,102], and $14 \%$ from Japan [103].

The incidence of cryptococcal infection among all patients with malignant neoplasms receiving multiple cycles of combined chemotherapeutic regimens, including corticosteroids, has been reported to be $1.3-2.7 \%$ [104]. Infections with the cryptococcal species account for about $2 \%$ of all infections of the central nervous system complicating hematological malignancies [105]. Patients with lymphoproliferative disorders, including malignant lymphoma, are also in a state of suppression of cell-mediated immunity, and intercurrent cryptococcal infections complicated with Acute Lymphocytic Leukemia(ALL), Adult T-cell Leukemia(ATL), Hairy Cell Leukemia(HCL), 
Chronic Lymphocytic Leukemia(CLL) and Hodgkin's lymphoma have been reported [104,106-109].

\section{CRYPTOCOCCOSIS IN IMMUNOCOMPROMISED PATIENTS}

Cryptococcosis as a result of $C$. neoformansis cosmopolitan and is a rare fungal infection that existed before the AIDS epidemic which has emerged as an important cause of illness and death in people infected with HIV in both developed and developing countries $[58,99,100]$. C. neoformans is also an opportunistic pathogen, which can cause cryptococcosis in patients with HIV infection and HIV-negative patients with immunological conditions predisposing to this fungal infection, such as a history of systemic corticosteroid therapy, immunosuppressive treatments, organ transplant, chronic organ failure (liver, lung, and kidney), malignancy, rheumatic diseases, systemic lupus erythematosus and diabetes mellitus [104,106-110].

Infection occurs via inhalation and primary infection is localized to the lung where there is dissemination to other organs including brain. Thus, the most common sites of infection are the central nervous system (CNS) and lungs; usual manifestations that are most commonly reported are pulmonary, meningoencephalitis, septicemia ocular and gastrointestinal [111-114]. Although the lung is the most likely point of entry of the fungus due to the inhalation of yeast cells or basidiospores by the patient, pulmonary cryptococcosis is diagnosed less frequently than meningitis in patients with AIDS [111]. Cryptococcus has a special tropism for the CNS, but the respiratory system is most commonly affected. However, these characteristics vary depending on the infecting strain and the host immune response, because some cryptococcal strains may be more virulent than others and the systemic inflammatory response varies from one patient to another [115].

Cryptococcal pneumonia may be either asymptomatic or symptomatic, with or without evidence of dissemination, and clinical manifestations include fever and cough that produces scant sputum, malaise, shortness of breath, and pleuritic pain; physical examination may reveal localized nodular lesions, with or without cavitations, segmental pneumonic infiltrate, patchy interstitial or alveolar infiltrates, pleural effusions, tachypnea, hilar masses and thoracic lymphadenopathy $[115,116]$. Cryptococcal pneumonia in immunocompromised patients may have a completely different and more rapid clinical course; C. neoformans tends to disseminate rapidly from the lungs or to reactivate from a primary focus, to eventually establish infection within the CNS, and patients often present with a meningeal rather than a pulmonary syndrome $[115,116]$. The clinical presentation of $C$. gattii in immunocompromised individuals is very similar to that of $C$. neoformans; however, the former is associated with more pulmonary and CNS cryptococcomas [117].

In this regards, pulmonary involvement by $C$. neoformans has been reported in 30-40\% of patients with meningoencephalitis [118]. Visnegarwala et al. [119] reported that of 210 patients with HIV infection and cryptococcal disease, $29(13.8 \%)$ had acute respiratory failure and the $C$. neoformans from at least one extrapulmonary or extraneural site was isolated of 10 patients, which carries an extremely high rate of mortality. Thus, these authors reported that acute respiratory failure associated with cryptococcal disease in AIDS patients is a marker of disseminated disease; this may suggest that the fulminant course of the disease in these patients was due to acute dissemination shortly after the acquisition of a primary pulmonary infection. However, it is unclear whether disseminated disease represents a progression or reactivation of pulmonary disease because many patients have no evidence of pulmonary involvement at the time of diagnosis of disseminated disease [120].

Disseminated disease is uncommon and when present almost always occurs in HIV-infected patients, but has also been reported in non-HIV-infected patients with alcoholic liver cirrhosis or those receiving chronic immunosuppressive medications [121-123]. The CNS is the most common site of disseminated cryptococcal infection; accordingly, Heyderman et al. [124] reported that the cryptococcal meningitis was the AIDS-defining illness in $78(88 \%)$ out of 89 patients studied. CNS invasion may be secondary to hematogenous infection or may represent reactivation disease similar to histoplasmosis or tuberculosis. Infection in most patients is typically characterized as subacute meningitis or meningoencephalitis and presents signs and symptoms such as headache, fever, lethargy, coma, personality changes, and memory loss over 2 to 4 weeks [125]. Moreover, cranial nerve palsies and papilledema are the most common ocular manifestations seen in patients with cryptococcal CNS invasion and most patients have severe visual loss $[125,126]$. Complications of CNS cryptococcosis include diffuse atrophy, hydrocephalus, and diffuse edema, while mass lesions include hydrocephalus, motor or sensory deficits, cerebellar dysfunction, seizures, diffuse edema; mass lesions and dementia [127].

Cryptococcal peritonitis must be regarded as an unusual clinical manifestation and has been proposed as a potential site of disseminated cryptococcosis $[9,112,113]$. Cirrhotic patients with ascites and oral or upper gastrointestinal tract bleeding are at risk of developing spontaneous cryptococcal peritonitis [112-114, 128,129]. Singh et al. [130] reported that the overall mortality rate of 33 patients with $C$. neoformans infection and cirrhosis, including liver transplant candidates, was $81 \%$ cases, and that the median time to death from admission was 13 days. These authors evidenced that cryptococcal peritonitis was present in $45.4 \%$ cases and that intraabdominal infection with $C$. neoformans was the most common site of disease manifestation in these patients. In addition, meningitis was present in $39 \%$ of patients, and $18 \%$ had pulmonary infection; also, that a total of 16 patients was treated with antifungal therapy and only $37 \%$ of these patients survived the fungal infection. Husain et al. [131] reported that $2.8 \%$ of organ transplant recipients can develop cryptococcal infections, resulting in a $42 \%$ mortality rate.

The administration of highly active antiretroviral therapy (HAART) has resulted in a decrease in the number of cases of AIDS-related cryptococcosis in developed countries, but Cryptococcus is still a major problem in developing country where HAART is not readily available. However, studies have described that primary antifungal prophylaxis for cryptococcosis is not routinely recommended in HIV- 
infected patients in the United States and Europe, but areas with limited HAART availability, high levels of antiretroviral drug resistance, and a high burden of disease might consider it or a preemptive strategy with serum cryptococcal antigen testing for asymptomatic antigenemia [39].

According to the World Health Organization (WHO), "early antiretroviral therapy (ART) initiation is the most important and cost-effective preventive strategy to reduce the incidence and high mortality associated with cryptococcal meningitis in HIV-infected adults, adolescents and children in resource-limited settings. Moreover, patients should ideally initiate ART at a CD4 count of 350 cells $/ \mathrm{mm}^{3}$, and definitely before a decline in the CD4 cell count to less than 200 cells $/ \mathrm{mm}^{3, "}[132]$.

\section{CRYPTOCOCCOSIS IN IMMUNOCOMPETENT PATIENTS}

Healthy individuals have been affected by $C$. gattii and $C$. neoformans, but these infections are more frequently caused by C. gattii [85, 86, 117, 133-137]. C. gattii may cause mild to severe clinical disease in the apparently healthy as well as in people with immunosuppressive conditions, including those with HIV infection, organ transplant recipients and patients with hematologic malignancies [133-137]. Thus, the major risk factor for acquiring C. gattii infection is a history of living in or travel to an endemic area, as well as an age greater than 50 years, smoking, the use of corticosteroids, and a history of cancer or chronic lung disease [138]. On the other hand, some studies have reported that approximately $25 \%$ of cases of cryptococcosis in immunocompetent individuals were associated with $C$. neoformans in the United States, and similar numbers have been found through the world [139-141].

Pulmonary cryptococcosis was described in apparently immunocompetent patients [142,143]. Pulmonary cryptococcosis caused by $C$. gattii usually presents as a regressive lung lesion which is usually undetected, or as a peripheral lung nodule which can be misdiagnosed as a malignant tumor. It typically evolves sub-acutely or chronically and is often confused with viral or bacterial meningoencephalitis or other infections, including tuberculosis [87]. In C. gattii infection, cerebral mass lesions and/or hydrocephalus, pulmonary mass lesions, increased neurological deficits, and a slower response to treatment are more common than in C. neoformans infection [134]. In addition, C. gattii disease is more often associated with neurologic sequelae, frequently requiring aggressive neurosurgical management [135].

Dora et al. [136] reported a case of disseminated cryptococcosis presenting as cutaneous lesions in an immunocompetent patient, which, after direct microscopy and culturing of cerebrospinal fluid, was found to be positive for $C$. gattii. In a study by Santos et al. [87] about infectious agents causing human disseminated cryptococcosis, it was shown that C. gattii was more frequently isolated from HIV negative patients and C. neoformans was predominantly isolated from the HIV-positive patients. Galanis et al. [137] have shown three case reports of cryptococcosis in HIV negative patients with confirmed infection by $C$. gattii. Georgi et al. [134] described a case report of a female patient who developed severe meningoencephalitis due to $C$. gattii infection. Gutierrez et al.
[144] reported a case of an immunocompetent patient with a one-month history of meningoencephalitis caused by $C$. gattii. Okamoto et al. [145] related a HIV negative patient in Japan infected with $C$. gattii.

To date, there is no effective vaccine to prevent cryptococcosis. In truth, the best way to prevent this disease is to not inhale the fungus. Therefore, the use of masks can be of help to prevent inhalation. This is even more useful in places where there are dried feces of pigeons, which are important sources of $C$. gattii. Moreover, forests with eucalyptus trees are an important area in which $C$. gattii lives and therefore constitute important sources of infection, mainly where logging operations occur; care regarding the inhalation of dusts is crucial in preventing the disease [146].

In the prevention of cryptococcosis, the serum or plasma containing the cryptococcal antigen is a good manner to identify on screening which, together with symptoms or signs associated with cryptococcal meningitis, indicate proceeding to a lumbar puncture with cerebrospinal fluid examination to exclude active cryptococcal disease [132].

\section{CONCLUSION}

Over the last decade, due to AIDS, cryptococcosis has increased and has become one of the major diseases of medical importance in both immunocompromised and immunocompetent individuals, particularly children. The major risk factors for Cryptococcus infection depend on the patient's immune status and the severity of the infection; unfortunately, treatment failures and mortality remain high. Consequently, future research will need to consider target molecules for intracellular survival and growth and/or cryptococcal virulence factors expressed during a host's parasitism to advance therapeutic schemes and also propose new strategies to improve anti-cryptococcal treatment.

\section{CONFLICT OF INTEREST}

The authors confirm that this article content has no conflict of interest.

\section{ACKNOWLEDGEMENTS}

Declared none.

\section{REFERENCES}

[1] Gupta G, Fries BC. Variability of phenotypic traits in Cryptococcus varieties and species and the resulting implications for pathogenesis. Future Microbiol 2010; 5(5): 775-87.

[2] Baker RD. The primary pulmonary lymph node complex of cryptococcosis. Am J Clin Pathol 1976; 65: 83-92.

[3] Lupo P, Chang YC, Kelsall BL, et al. The presence of capsule in Cryptococcus neoformans influences the gene expression profile in dendritic cells during interaction with the fungus. Infect Immun 2008; 76 (4): 1581-9.

[4] Nichols CB, Perfect ZH, Alspaugh JA. A Ras1-Cdc24 signal transduction pathway mediates thermotolerance in the fungal pathogen Cryptococcus neoformans. Mol Microbiol 2007; 63: 111830 .

[5] Kwon-Chung KJ, Edman JC, Wickes BL. Genetic association of mating types and virulence in Cryptococcus neoformans. Infect Immun 1992; 60: 602-5.

[6] Jiang N, Xiao D, Zhang D, Sun N, Yan B, Zhu X. Negative roles of a novel nitrogen metabolite repression-related gene, TAR1, in laccase production and nitrate utilization by the basidiomycete Cryptococcus neoformans. Appl Environ Microbiol 2009; 75: 6777-82. 
[7] Panepinto J, Komperda K, Frases S, et al. Sec6-dependent sorting of fungal extracellular exosomes and laccase of Cryptococcus neoformans. Mol Microbiol 2009; 71: 1165-76.

[8] Zaragoza O, Rodrigues ML, De Jesus M, Frases S, Dadachova E, Casadevall A. The capsule of the fungal pathogen Cryptococcus neoformans. Adv Appl Microbiol 2009; 68: 133-216.

[9] Park BJ, Wannemuehler KA, Marston BJ, Govender N, Pappas PG, Chiller TM. Estimation of the current global burden of cryptococcal meningitis among persons living with HIV/AIDS. AIDS 2009; 23(4): 525-30.

[10] Datta K, Bartlett KH, Baer R, et al. Spread of Cryptococcus gattii into Pacific Northweast Region of the United States. Emerg Infect Dis 2009; 15(8): 1185- 91.

[11] Tintelnot K, Lemmer K, Losert H, Schar G, Polak A. Follow-up of epidemiological data of cryptococcosis in Austria, Germany and Switzerland with special focus on the characterization of clinical isolates. Myc 2004; 47: 455-64.

[12] Kwon-Chung KJ, Bennet JE. Epidemiologic differences between the two varieties of cryptococcus neoformans. Am J Epidemiol 1984; 120: $123-30$.

[13] Frasés S, Ferrer C, Sánchez M, Colom-Valiente M. Molecular epidemiology of isolates of the Cryptococcus neoformans species complex from Spain. Rev Iberoam Micol 2009; 26(2): 112-7.

[14] Casadevall A, Perfect JR. Cryptococcus neoformans. American Society for Microbiology. Press: Washington, DC 1998.

[15] Chen S, Sorrell T, Nimmo G, et al. Epidemiology and host- and variety-dependent characteristics of infection due to Cryptococcus neoformans in Australia and New Zealand. Clin Infect Dis 2000; 31: 499-508.

[16] Kwon-Chung KJ, Boekhout T, Fell JW, Diaz M. Proposal to conserve the name Cryptococcus gattii against $C$. hondurianus and $C$. bacillisporus (Basidiomycota, Hymenomycetes, Tremellomycetidae). Taxon 2002; 51: 804-6.

[17] Sanfelice F. Contributo alla morfologia e biolgia dei blastomiceti che si sviluppano nei succi di alcuni frutti. Annli di Igieni: medicina preventiva e di comitá 1894; 4: 463-95.

[18] Vuillemin P. Les blastomycètes pathogènes. Revue Generale des Sciences Pures et Appliquees 1901; 12: 732-51.

[19] Kwon-Chung KJ, A new genus, Filobasidiella, the perfect state of Cryptococcus neoformans. Mycol 1975; 67: 1197-1200.

[20] Litvintseva AP, Lin X, Templeton I, Heitman J, Mitchell TG. Many globally isolated $\mathrm{AD}$ hybrid strains of Cryptococcus neoformans originated in Africa. PLoS Pathogens 2007; 3 (8): e114.

[21] Kwon-Chung KJ. A new species of Filobasidiella, the sexual state of Cryptococcus neoformans B and C serotypes. Mycol 1976; 68: 9436.

[22] Ellis DH, Pfeiffer TJ. Natural habitat of Cryptococcus neoformans var. gattii. J Clin Microbiol 1990; 28: 1642-4.

[23] Wickes BL, Moore TDE, Kwon-Chung KJ. Comparison of the electrophoretic karyotypes and chromosomal location of ten genes in the two varieties of Cryptococcus neoforrnans. Microbiol 1994; 140: 543-50.

[24] Kwon-Chung KJ, Wickes BL, Booth JL, Vishniac HS, Bennett JE. Urease inhibition by EDTA in the two varieties of Cryptococcus neoformans. Infec Immun 1987; 55: 1751-4.

[25] Jain N, Fries BC. Phenotypic Switching of Cryptococcus neoformans and Cryptococcus gattii. Mycopathol 2008; 166 (4): 181-8.

[26] Kwon-Chung KJ, Bennett JE, Theodore TS. Cryptococcus bacillisporus sp. nov.: Serotype B-C of Cryptococcus neoformans. Int J Syst Bacteriol 1978; 28: 616-20.

[27] Ngamskulrungroj P, Gilgado F, Faganello J. et al. Genetic diversity of the cryptococcus species complex suggests that cryptococcus gattii deserves to have varieties. PLoS ONE 2009; 4 (6): e5862.

[28] Meyer W, Aanensen DM, Boekhout T. et al. Consensus multi-locus sequence typing scheme for Cryptococcus neoformans and Cryptococcus gattii. Med Mycol 2009; 47(6): 561-70.

[29] Ngamskulrungroj P, Serena C, Gilgado F, Malik R, Meyer W. Global VGIIa isolates are of comparable virulence to the major fatal Cryptococcus gattii Vancouver Island outbreak genotype. Clin Microbiol Infect 2011; 17(2): 251-8.

[30] Bauwens L, Swinne D, De Vroey C, Meurichy W. Isolation of Cryptococcus neoformans var. neoformans in the aviaries of the Antwerp zoological gardens. Mykosen 1986; 29(7): 291-4.

[31] Kwon-Chung KJ, Bennett JE. Cryptococcosis. In: Kwon-Chung KJ, Bennett JE, Eds. Medical Mycology. Philadelphia: Lea \& Febiger 1992; pp. 397-446.
[32] Nielsen K, De Obaldia AL, Heitman J. Cryptococcus neoformans mates on pigeon guano: implications for the realized ecological niche and globalization. Eukar Cell 2007; 6(6): 949-59.

[33] Brito AM, Castilho EA, Szwarcwald CL. AIDS e infecção pelo HIV no Brasil: uma epidemia multifacetada. Rev Soc Bras Med Trop 2001; 34: 207-17.

[34] Yildiran ST, Saracli MA, Gonlum A, Gun H. Isolation of Cryptococcus neoformans var. neoformans from pigeon droppings collected throughout Turkey. Med Mycol 1998; 36: 391-4.

[35] Lazera MS, Pires FDA, Camillo-Coura L, et al. Natural habitat of Cryptococcus neoformans var. neoformans in decaying wood forming hollows in living trees. J Med Vet Mycol 1996; 34: 127-31.

[36] Randhawa HS, Mussa AY, Khan ZU. Decaying wood in tree trunk hollows as a natural substrate for Cryptococcus neoformans and other yeast-like fungi of clinical interest. Mycopathol 2000; 151: 63-9.

[37] Speed B, Dunt D. Clinical and host differences between infections with the two varieties of Cryptococcus neoformans. Clin Infect Dis 1995; $21: 28-34$.

[38] Seaton RA, Naraqi S, Wembri JP, Warrell DA. Predictors of outcome in Cryptococcus neoformans var. gattii meningitis. Q J Med 1996; 89: 423-8.

[39] Perfect JR, Dismukes WE, Dromer F, et al. Clinical Practice Guidelines for the Management of Cryptococcal Disease: 2010 Update by the Infectious Diseases Society of America. Clin Infect Dis 2010; 50: 291-322.

[40] Sorrell TC. Cryptococcus neoformans variety gattii. Med Mycol 2001; 39(2): 155-68.

[41] Mitchell TG, Perfect JR. Cryptococcosis in the era of AIDS-100 years after the discovery of Cryptococcus neoformans. Clin Microbiol Rev 1995; 8: 515-48.

[42] Stephen C, Lester S, Black W, Fyfe M, Raverty S. Multispecies outbreak of cryptococcosis on southern Vancouver Island, British Columbia. Can Vet J 2002; 43(10): 792-94.

[43] Kidd SE, Hagen F, Tscharke RL, et al. A rare genotype of Cryptococcus gattii caused the cryptococcosis outbreak on Vancouver Island (British Columbia, Canada). Proc Natl Acad Sci USA 2004; 101: 17258-263.

[44] Ellis DH, Pfeiffer TJ. Ecology, life cycle and infectious propagule of Cryptococcus neoformans. Lancet 1990; 336: 923-5.

[45] Tay ST, Rohani MY, Soo Hoo TS, Hamimah H. Epidemiology of cryptococcosis in Malaysia. Mycoses 2009; 53: 509-14.

[46] Abegg MA, Cella FL, Faganello J, Valente P, Schrank A, Vainstein MH. Cryptococcus neoformans and Cryptococcus gattii isolated from the excreta of psittaciformes in a southern Brazilian zoological garden. Mycopathol 2006; 161: 83-91.

[47] Lazera MS, Cavalcanti MA, Trilles L, Nishikawa MM, Wanke B. Cryptococcus neoformans var. gattii-evidence for a natural habitat related to decaying wood in a pottery tree hollow. Med Mycol 1998; 36: $119-122$.

[48] Duncan C, Schwantje H, Stephen C, Campbell J, Bartlett K. Cryptococcus gattii in wildlife of Vancouver Island, British Columbia, Canada. J Wildl Dis 2006; 42(1): 175-78.

[49] Saez H, Rinjard J, Battesti MR. Cryptococcose chez um fennec (Fennecus zerda). Bull Soc Fr Mycol Med 1978; 7: 69-72.

[50] McNamara TS, Cook RA, Behler JL, Ajello L, Padhye AA. Cryptococcosis in a common anaconda (Eunectes murinus). J Zoo Wildl Med 1994; 25: 128-32

[51] Wayne LB, Jardine JE, Espie IW. Pulmonary cryptococcoma and cryptococcal meningoencephalomyelitis in a King cheetah (Acinonyx jubatus). J Zoo Wildl Med 1997; 28: 485-90.

[52] Burek K. Mycotic diseases. In: Williams ES, Barker IK, Eds. Infectious Diseases of Wild Mammals. London: Manson Publishing, The Veterinary Press 2001; pp. 520-2.

[53] Bauwens L, Vercammen F, Wuytack C, Van Looveren K, Swinne D Isolation of Cryptococcus neoformans in Antwerp Zoo's nocturnal house. Mycoses 2004; 47: 292-6.

[54] Hubálek Z. Emerging human infectious diseases: anthroponoses, zoonoses, and sapronoses. Emerg Infect Dis 2003; 9: 403-4.

[55] Malik M, Krockenberger M, O'Brien CR, Martin P, Wigney D, Medleau L. Cryptococcosis. In: Greene CE, Ed. Infectious diseases of the dog and cat. St. Louis: Saunders Elsevier 2006; pp. 584-98.

[56] Cabañes FJ. Mycoses and zoonoses: Cryptococcus spp. Rev Iberoam Micol 2008; 25: S1-S3.

[57] Duncan C, Stephen C, Lester S, Bartlett KH. Follow-up study of dogs and cats with asymptomatic Cryptococcus gattii infection or nasal colonization. Med Mycol 2005; 43: 663-6. 
[58] Idnurm A, Bahn YS, Nielsen K, Lin X, Fraser JA, Heitman J. Deciphering the model pathogenic fungus Cryptococcus neoformans. Nat Rev Microbiol 2005; 3: 753-64.

[59] Ellis D, Pfeiffer T, The ecology of Cryptococcus neoformans. Eur J Epidemiol 1992; 8: 321-25.

[60] Vilcins I, Krockenberger M, Agus H, Carter D. Environmental sampling for Cryptococcus neoformans var. gattii from the Blue Mountains National Park, Sydney, Australia. Med Mycol 2002; 40: 53-60.

[61] Granados DP, Castañeda E. Isolation and characterization of Cryptococcus neoformans varieties recovered from natural sources in Bogota, Colombia, and study of ecological conditions in the area. Microbial Ecol 2005; 49: 282-90.

[62] Ruma-Haynes P, Brownlee AG, Sorrell TC. A rapid method for detecting extracellular proteinase activity in Cryptococcus neoformans and a survey of 63 isolates. J Med Microbiol 2000; 49: 733-37.

[63] Olszewski MA, Zhang Y, Huffnagle GB. Mechanisms of cryptococcal virulence and persistence. Fut Microbiol 2010; 5(8): 1269-88.

[64] Fromtling RA, Shadomy HJ, Jacobson ES. Decreased virulence in stable, acapsular mutants of Cryptococcus neoformans. Mycopathol 1982; 79(1): 23-9.

[65] Lin X. Cryptococcus neoformans: morphogenesis, infection, and evolution", Infec Gen Evol 2009; 9: 401-16.

[66] Vecchiarelli A, Pietrella D, Lupo P, Bistoni F, McFadden DC, Casadevall A. The polysaccharide capsule of Cryptococcus neoformans interferes with human dendritic cell maturation and activation. J Leuk Biol 2003; 74(3): 370-78.

[67] Siegemund S, Alber G. Cryptococcus neoformans activates bone marrow-derived conventional dendritic cells rather than plasmacytoid dendritic cells and downregulates macrophages. FEMS Immunol Med Microbiol 2008; 52(3): 417-27.

[68] Voelz K, May RC. Cryptococcal interactions with the host immune system. Eukar Cell 2010; 9: 835-46.

[69] Bicanic T, Harrison TS. Cryptococcal meningitis. Br Med Bull 2004; 72(1): 99-118

[70] Wang Y, Aisen P, Casadevall A. Cryptococcus neoformans melanin and virulence: mechanism of action. Infec Immun 1995; 63(8): 31316.

[71] Zhu X, Williamson PR. Role of laccase in the biology and virulence of Cryptococcus neoformans. FEMS Yeast Res 2004; 5: 1-10.

[72] Noverr MC, Cox GM, Perfect JR, Huffnagle GB. Role of PLB1 in pulmonary inflammation and cryptococcal eicosanoid production. Infec Immun 2003; 71(3): 1538-47.

[73] Rodrigues ML, Nakayasu ES, Oliveira DL. et al. Extracellular vesicles produced by Cryptococcus neoformans contain protein components associated with virulence. Eukar Cell 2008; 7: 58-67.

[74] Osterholzer JJ, Surana R, Milam JE, et al. Cryptococcal urease promotes the accumulation of immature dendritic cells and a nonprotective T2 immune response within the lung. A J Pathol 2009; 174 (3): 932-43.

[75] Jones Jr SK, Bennett RJ. Fungal Mating Pheromones: Choreographing the Dating Game. Fungal Genet Biol 2011; 48(7): 668-76.

[76] Cogliati F, Barchiesi F, Spreghini E, Tortorano AM.. Heterozygosis and pathogenicity of Cryptococcus neoformans AD-hybrid isolates. Mycopathol 2012; 173(5-6): 347-57.

[77] Wu G, Vilchez RA, Eidelman B, Fung J, Kormos R, Kusne S. Cryptococcal meningitis: an analysis among 5,521 consecutive organ transplant recipients. Transpl Infect Dis 2002; 4: 183-88.

[78] Junaid SA, Olabode AO, Udeani TKC, Aikoye S. Prevalence of Pulmonary Cryptococcosis in HIV/AIDS Patients. Afr J Infect Dis 2008, 2(2): 74-9.

[79] Yoo SD, Worodria W, Davis JL. The prevalence and clinical course of HIV-associated pulmonary cryptococcosis in Uganda. J Acquired Immune Defic Synd 2010, 54(3): 269-74.

[80] Balkhair AA, Al-Muharrmi ZK, Ganguly S, Al-Jabri AA. Spectrum of AIDS Defining Opportunistic Infections in a Series of 77 Hospitalised HIV-infected Omani Patients. Sultan Qaboos Univ Med J 2012; 12(4): 442-48

[81] Ayyagari A, Sharma AK, Prasad KN, et al. Spectrum of Opportunistic infections in HIV infected cases in a Tertiary care Hospital. Indian J Med Microbiol 1999; 17: 78-80.
[82] Satishchandra P, Nalini A, Gourie-Devi M, et al. Profile of neurological disorders associated with HIV/ AIDS from Bangalore, South India (1986-96). Indian J Med Res 2000; 111: 14-23.

[83] Debourgogne A, Iriart X, Blanchet $\mathrm{D}$, et al. Characteristics and specificities of Cryptococcus infections in French Guiana, 19982008. Med Mycol 2011; 49(8): 864-71.

[84] Igreja RP, Lazera MS, Wanke B, Galhardo MC, Kidd SE, Meyer W, Molecular epidemiology of Cryptococcus neoformans isolates from AIDS patients of the Brazilian city, Rio de Janeiro, Med Mycol 2004; 42: $229-38$

[85] Galanis E, Macdougall L, Kidd S, et al. Epidemiology of Cryptococcus gattii, British Columbia, Canada, 1999-2007. Emerg Infect Dis 2010; 16(2): 251-7.

[86] Byrnes EJ 3rd, Li W, Lewit Y, et al. Emergence and Pathogenicity of Highly Virulent Cryptococcus gattii Genotypes in the Northwest United States. PLoS Pathog 2010; 6(4): e1000850.

[87] Santos WRA, Meyer W, Wanke B, et al. Primary endemic Cryptococcosis gattii by molecular type VGII in the state of Pará, Brazil. Mem Inst Oswaldo Cruz 2008; 103(8): 813-8.

[88] Trilles L, Lazéra Mdos S, Wanke B, et al. Regional pattern of the molecular types of Cryptococcus neoformans and Cryptococcus gattii in Brazil. Mem Inst Oswaldo Cruz 2008; 103: 455-62.

[89] Litvintseva AP, Thakur R, Reller LB, Mitchell TG. Prevalence of clinical isolates of Cryptococcus gattii serotype $\mathrm{C}$ among patients with AIDS in sub-Saharan Africa. J Infect Dis 2005; 192 (5): 888-92.

[90] Pyrgos V, Seitz AE, Steiner CA, Prevots DR, Williamson PR. Epidemiology of Cryptococcal Meningitis in the US: 1997-2009. PLoS One 2013; 8(2): e56269.

[91] Pinner RW, Hajjeh RA, Powderly WG. Prospects for preventing cryptococcosis in persons infected with human immunodeficiency virus. Clin Infect Dis 1995; 21 (Suppl 1): S103-7.

[92] McCarthy KM, Morgan J, Wannemuehler KA, et al. Populationbased surveillance for cryptococcosis in an antiretroviral-naive South African province with a high HIV seroprevalence. AIDS 2006; 20(17): 2199-206.

[93] Rajasingham R, Boulware DR. Reconsidering Cryptococcal Antigen Screening in the U.S. Among Persons with CD4 $<100$ cells $/ \mathrm{mcL}$ Clin Infect Dis 2012; 55(12): 1742-4.

[94] Dromer F, Mathoulin-Pélissier S, Launay O, Lortholary O; French Cryptococcosis Study Group. Determinants of Disease Presentation and Outcome during Cryptococcosis: the CryptoA/D Study. PLoS Med 2007; 4(2): e21.

[95] Mirza SA, Phelan M, Rimland D, et al. The changing epidemiology of cryptococcosis: an update from population-based active surveillance in 2 large metropolitan areas, 1992-2000. Clin Infect Dis 2003; 36(6): 789-94

[96] Lanjewar DN. The spectrum of clinical and pathological manifestations of AIDS in a consecutive series of 236 autopsied cases in Mumbai, India. Pathol Res Int 2011; 2011: 547618.

[97] Klatt EC, Nichols L, Noguchi TT. Evolving trends revealed by autopsies of patients with the acquired immunodeficiency syndrome: 565 autopsies in adults with the acquired immunodeficiency syndrome, Los Angeles, Calif, 1992-1993. Arch Pathol Lab Med 1994; 118(9): 884-90.

[98] Mohar A, Romo J, Salido F, et al. The spectrum of clinical and pathological manifestations of AIDS in a consecutive series of autopsied patients in Mexico. AIDS 1992; 6(5): 467-73.

[99] Nelson AM, Perriëns JH, Kapita B, et al. A clinical and pathological comparison of the WHO and CDC case definitions for AIDS in Kinshasa, Zaire: is passive surveillance valid? AIDS 1993; 7(9): $1241-5$.

[100] Lucas SB, Hounnou A, Peacock C, et al. The mortality and pathology of HIV infection in a West African city. AIDS 1993; 7(12): 1569-79.

[101] Cury PM, Pulido CF, Furtado VM, da Palma FM. Autopsy findings in AIDS patients from a reference hospital in Brazil: analysis of 92 cases. Pathol Res Pract 2003; 199(12): 811-4.

[102] Soeiro Ade M, Hovnanian AL, Parra ER, Canzian M, Capelozzi VL. Post-mortem histological pulmonary analysis in patients with HIV/AIDS. Clinics 2008; 63(4): 497-502

[103] Ohtomo K, Wang S, Masunaga A, Aikichi, Iwamoto, Sugawara I Secondary infections of AIDS autopsy cases in Japan with special emphasis on Mycobacterium avium intracellulare complex infection. Tohoku J Exp Med 2000; 192(2): 99-109.

[104] Korfel A, Menssen HD, Schwartz S, Thiel E. Cryptococcus in Hodgkin's disease: description of two cases and review of the literature. Ann Hematol 1998; 76(6): 283-6. 
[105] Escudier E, Cordonnier C, Poirier J. Infections of the central nervous system in malignant hemopathies. Rev Neurol (Paris) 1986; 142(2): 116-25.

[106] Dinçol G, Kahraman R. Cryptococcus neoformans meningitis in a patient with hairy cell Leukemia. Am J Hematol 2006; 81(5): 387.

[107] Reisfeld-Zadok S, Elis A, Szyper-Kravitz M, Chowers M, Lishner M. Cryptococcal meningitis in chronic lymphocytic leukemia patients. Isr Med Assoc J 2009; 11(7): 437-9.

[108] Rhew DC, Gaultier CR, Daar ES, Zakowski PC, Said J. Infections in patients with chronic adult T-cell leukemia/lymphoma: case report and review. Clin Infect Dis 1995; 21(4): 1014-6.

[109] Hirai Y, Ainoda Y, Shoji T, et al. Disseminated Cryptococcosis in a Non-Hodgkin's Lymphoma Patient with Late-Onset Neutropenia Following Rituximab-CHOP Chemotherapy: A Case Report and Literature Review. Mycopathologia 2011; 172(3): 227-32.

[110] Casadevall A. Cryptococcosis. In: Fauci AS, Braunwald E, Kasper DL, et al., Ed. Harrison's principles of internal medicine. $17^{\text {th }}$ ed. New York: McGraw-Hill Medical Publishing Division 2008; pp. 1251-3.

[111] Jean SS, Fang CT, Shau WY, et al. Cryptococcaemia: Clinical features and prognostic factors. QJM 2002; 95(8): 511-8.

[112] Yehia BR, Eberlein M, Sisson SD, Hager DN. Disseminated cryptococcosis with meningitis, peritonitis, and cryptococcemia in a HIV-negative patient with cirrhosis: A case report. Cases J 2009; 28; 2: 170 .

[113] Saha S, Agarwal N, Srivastava A, Kumar A. Perforation peritonitis due to gastrointestinal cryptococcosis as an initial presentation in an AIDS patient. Singapore Med J 2008; 49(11): e305-7.

[114] Washington K, Gottfried MR, Wilson ML. Gastrointestinal cryptococcosis. Mod Pathol 1991; 4(6): 707-11.

[115] Guy JP, Raza S, Bondi E, Rosen Y, Kim DS, Berger BJ. Cryptococcus pneumonia presenting in an immunocompetent host with pulmonary asbestosis: a case report. J Med Case Rep 2012; 6(1): 170 .

[116] Onen CL. Clinical Diagnosis of AIDS and HIV-Related Diseases. AIDS Afr 2002; 297-321.

[117] Lochhart SR, Harris J. Cryptococcus gattii: Clinical Importance and Emergence in North America. Cur Fungal Infec Rep 2010; 4(3): 1517.

[118] Meyohas MC, Roux P, Bollens D, et al. Pulmonary Cryptococcosis: Localized and Disseminated Infections in 27 Patients with AIDS. Clin Infect Dis 1995; 21(3): 628-33.

[119] Visnegarwala F, Graviss EA, Lacke CE, et al. Acute respiratory failure associated with cryptococcosis in patients with AIDS: analysis of predictive factors. Clin Infect Dis 1998; 27(5): 1231-7.

[120] van der Horst CM, Saag MS, Cloud GA. et al. Treatment of cryptococcal meningitis associated with the acquired immunodeficiency syndrome. National Institute of Allergy and Infectious Diseases Mycoses Study Group and AIDS Clinical Trials Group. N Engl J Med 1997; 337(1): 15-21.

[121] Yinnon AM, Solages A, Treanor JJ. Cryptococcal peritonitis: report of a case developing during continuous ambulatory peritoneal dialysis and review of the literature. Clin Infect Dis 1993; 17: 736-41.

[122] Salvaggio MR, Pappas PG. Current Concepts in the Management of Fungal Peritonitis. Curr Infect Dis Rep 2003; 5(2): 120-4.

[123] Albert-Braun S, Venema F, Bausch J, Hunfeld KP, Schäfer V. Cryptococcus neoformans Peritonitis in a Patient with Alcoholic Cirrhosis: Case Report and Review of the Literature. Infection 2005; 33(4): 282-8

[124] Heyderman RS, Gangaidzo IT, Hakim JG, et al. Cryptococcal Meningitis in Human Immunodeficiency Virus-Infected Patients in Harare, Zimbabwe. Clin Infect Dis 1998; 26(2): 284-9.

[125] Mitchell TG, Perfect JR. Cryptococcosis in the Era of AIDS-100 Years after the Discovery of Cryptococcus neoformans. Clin Microbiol Rev 1995; 8(4): 515-48.

[126] Denning DW, Armstrong RW, Fishman M, Stevens DA. Endophthalmitis in a patient with disseminated cryptococcosis and
AIDS who was treated with itraconazole. Rev Infect Dis 1991; 13(6): 1126-30.

[127] Popovich MJ, Arthur RH, Helmer E. CT of intracranial cryptococcosis. AJR. 154(3): 603-606.

[128] Stiefel P, Pamies E, Miranda ML, Martin-Sanz MV, FernandezMoyano A, Villar J. Cryptococcal peritonitis: Report of a case and review of the literature. Hepatogastroenterology 1999; 46(27): 161822

[129] Park WB, Choe YJ, Lee KD, et al. Spontaneous Cryptococcal Peritonitis in Patients with Liver Cirrhosis. Am J Med 2006; 119(2): 169-71.

[130] Singh N, Husain S, De Vera M, Gayowski T, Cacciarelli TV Cryptococcus neoformans infection in patients with cirrhosis, including liver transplant candidates. Medicine 2004; 83(3): 188-92

[131] Husain S, Wagener MM, Singh N. Cryptococcus neoformans infection in organ transplant recipients: variables influencing clinical characteristics and outcome. Emerg Infect Dis 2001; 7(3): 375-81.

[132] World Health Organization (WHO). Rapid Advice: Diagnosis, Prevention and Management of Cryptococcal Disease in HIVinfected Adults, Adolescents and Children. Geneva: WHO 2011. Available at: http: //whqlibdoc.who.int/publication/2011/97892415 02979_eng.pdf [Accessed 2013 May 04]

[133] Chaturvedi S, Dyavaiah M, Larsen RA, Chaturvedi V. Cryptococcus gattii in AIDS patients, southern California. Emerg Infect Dis 2005; 11(11): 1686-92.

[134] Georgi A, Schneemann M, Tintelnot K, et al. Cryptococcus gattii Meningoencephalitis in an Immunocompetent Person 13 Months after Exposure. Infect 2009; 37(4): 370-3.

[135] Datta K, Bartlett KH, Baer R, et al. Spread of Cryptococcus gattii into Pacific Northwest region of the United States. Emerg Infect Dis 2009; 15(8): 1185-91.

[136] Dora JM, Kelbert S, Deutschendorf C, et al. Cutaneous cryptococccosis due to Cryptococcus gattii in immunocompetent hosts: Case report and review. Mycopathologia 2006; 161(4): 235-8.

[137] Galanis E, Hoang L, Kibsey P, Morshed M, Phillips P. Clinical presentation, diagnosis, and management of Cryptococcus gattii cases: Lessons learned from British Columbia. Can J Infect Dis Med Microbiol 2009; 20(1): 23-8.

[138] Bartlett KH, Cheng PY, Duncan C, et al. A decade of experience: Cryptococcus gattii in British Columbia. Mycopathologia 2012 173(5-6): 311-9.

[139] Zahra LV, Azzopardi CM, Scott G. Cryptococcal meningitis in two apparently immunocompetent Maltese patients. Mycoses 2004; 47(34): $168-73$

[140] Hofman V, Venissac N, Mouroux C, Butori C, Mouroux J, Hofman P. Disseminated pulmonary infection due to Cryptococcus neoformans in a non immunocompromised patient. Ann Pathol 2004; 24(2): 187-91.

[141] Chen J, Varma A, Diaz MR, Litvintseva AP, Wollenberg KK, KwonChung KJ. Cryptococcus neoformans strains and infection in apparently immunocompetent patients. Emerg Infect Dis 2008; 14(5): 755-62.

[142] Campbell GD. Primary pulmonary cryptococcosis. Am Rev Respir Dis 1966; 94(2): 236-43.

[143] Chu HQ, Li HP, He GJ: Analysis of 23 cases of pulmonary cryptococcosis. Chin Med J (Engl) 2004, 117: 1425-1427.

[144] Gutierrez EL, Valqui W, Vilchez L, et al. Cryptococcus gatti meningoencephalitis in an HIV-negative patient from the Peruvian Andes. Rev Soc Bras Med Trop 2010; 43(4): 469-71.

[145] Okamoto K, Hatakeyama S, Itoyama S, et al. Cryptococcus gattii Genotype VGIIa Infection in Man, Japan, 2007. Emerg Infect Dis 2010; 16(7): 1155-7.

[146] eMedicine.com. [homepage on the Internet]. Davis CP. Cryptococcosis. Available: http: //www.emedicinehealth.com/crypt ococcosis /page9_em.htm\#cryptococcosis_prevention [updated 2010 April 28, accessed 2013 May 06].

This is an open access article licensed under the terms of the Creative Commons Attribution Non-Commercial License (http: //creativecommons.org/licenses/bync/3.0/) which permits unrestricted, non-commercial use, distribution and reproduction in any medium, provided the work is properly cited. 